\title{
STRATEGI KOPING DENGAN PENDEKATAN SPIRITUAL PADA PASIEN CHRONIC KIDNEY DISEASE (CKD) YANG MENJALANI HEMODIALIS : STUDI FENOMENOLOGI
}

\section{Coping Strategies with Spiritual Approaches in Chronic Kidney Disease (CKD) Patients Undergoing Hemodialysis: Phenomenology}

\author{
Supriyono* $^{* 1}$, Kusnanto ${ }^{2}$, Zaenal Abidin ${ }^{1}$ \\ 1. Mahasiswa Fakultas Keperawatan Universitas Airlangga \\ 2. Fakultas Keperawatan Universitas Airlangga
}

\section{Riwayat artikel}

Diajukan: 5 Agustus 2019

Diterima: 28 Maret 2020

\section{Penulis Korespondensi: \\ - Supriyono \\ - Fakultas Keperawatan, \\ Universitas Airlangga \\ supriyonorsuhaji70@gm \\ ail.com}

\section{Kata Kunci:}

Mekanisme koping, CKD, Hemodialisis, Fenomenologi, Pendekatan Spiritualitas

\begin{abstract}
Abstrak
Pendahuluan: Stress yang dihadapi oleh pasien dengan CKD yang menjalani hemodialisis dapat berakibat pada pemburukan kondisi pasien sehingga penting adanya upaya dalam mengatasi stress yang dialami atau mekanisme koping. Tujuan penelitian ini adalah mengeksplorasi mekanisme koping dengan pendekatan spiritual pasien CKD yang menjalani hemodialisis. Penelitian ini merupakan studi fenomenologi deskriptif. Metode: Metode pengumpulan data dilakukan dengan wawancara mendalam. Partisipan dalam penelitian ini berjumlah 15 orang yang berasal dari unit hemodialisis dengan kriteria partisipan berusia lebih dari 25 tahun, menjalani hemodialisis lebih dari 3 bulan, kesadaran compos mentis dan reguler menjalani hemodialisa 2-3 kali seminggu. Data yang diperoleh dianalisis dengan pendekatan Colaizzi. Hasil: Dari hasil analisis penelitian di temukan 2 tema yang mencerminkan fenomena yang diteliti. Tematema tersebut antara lain adalah pendekatan sipritual dan pendekatan medis. Diskusi: Pendekatan spiritual lebih dominan dilakukan oleh partisipan dan merasakan manfaat dari pendekatan tersebut sehingga penting dilakukan intervensi berbasis spiritual untuk mengatasi stress yang dialami oleh pasien CKD yang menjalani hemodialisis.
\end{abstract}

Abstract
Introduction Stress faced by patients with CKD undergoing hemodialysis can
result in worsening the patient's condition so it is important that efforts are made
to deal with stress experienced or coping mechanisms. The purpose of this study
was to explore coping mechanisms with the spiritual approach of CKD patients
undergoing hemodialysis. This research is a descriptive phenomenology study.
Method: The method of data collection is done by in-depth interviews.
Participants in this study were 15 people who came from the hemodialysis unit
with the criteria of participants aged more than 25 years, undergoing
hemodialysis for more than 3 months, compos mentis and regular consciousness
undergoing hemodialysis $2-3$ times a week. The data obtained were analyzed using
the Colaizzi approach. Result: From the results of the research analysis found 2
themes that reflect the phenomenon under study. These themes include a spiritual
approach and a medical approach. Discussion: The spiritual approach is more
dominant for the participants and feels the benefits of the approach so it is
important to do a spiritual-based intervention to overcome the stress experienced
by CKD patients undergoing hemodialysis..

\section{PENDAHULUAN}

Hemodialisis (HD) merupakan suatu proses terapi pengganti ginjal yang berfungsi mengoreksi gangguan keseimbangan cairan dan elektrolit pada pasien gagal ginjal, meskipun begitu pasien gagal ginjal tetap akan merasakan berbagai keluhan akibat gagal ginjal kronik yang dialaminya yaitu masalah hematologi, nutrisi, endokrin, muskuloskeletal, dan respon imun yang abnormal. Penyebab utama hemodialisa adalah penyekit ginjal kronik (PGK)(Shahgholian and Yousefi, 2018). Prevalensi penyakit ginjal kronik (PGK) di 
Indonesia sebesar $(0,2 \%)$ dari penduduk indonesia. Jika saat ini penduduk Indonesia sebesar 252.124.458 jiwa maka terdapat 504.248 jiwa yang menderita penyakit ginjal kronik. Hanya $(60 \%)$ dari pasien penyakit ginjal kronik stadium $\mathrm{V}$ tersebut yang menjalani terapi dialisis. Di provinsi Sumatera Barat prevalensi penyakit ginjal kronik yaitu $(0,2 \%)$ dari pasien penyakit ginjal kronik di Indonesia mencakup pasien yang yang menjalani pengobatan terapi pengganti ginjal, dialisis peritoneal, dan hemodialisis. Hemodialisis adalah terapi yang paling sering dilakukan pada pasien penyakit ginjal kronik diseluruh dunia, termasuk di Pasien dengan PGK seringkali mengalami stress akibat proses penyakit yang dialami sehingga dibutuhkan mekanisme koping yang baik dalam mengatasinya. Mekanisme koping seringkali identik dengan spiritualitas seseorang. Model holistik mengatakan bahwa semua penyakit yang memiliki komponen psikosomatik, dan biologis, faktor psikologis, sosial, dan spiritual selalu berkontribusi dalam gejala- gejala penyakitnya (Arafah et al., 2017). Dimensi spiritual dalam model biopsiko-sosial-spiritual menggabungkan spiritual dalam konteks yang lebih luas yaitu nilai-nilai, makna dan tujuan hidup. Sebagai perawat yang bertugas di ruang hemodialisa diharapkan mampu memanfaatkan kekuatan spiritualitas, merawat kesehatan fisik, pikiran, dan jiwa, serta berusaha untuk menciptakan kondisi budaya organisasi yang menumbuhkan spiritualitas. Sebagai langkah utama mengupayakan penyembuhan adalah menciptakan lingkungan yang berusaha memahami spiritualitas yang nantinya akan mempengaruhi kehidupan pasien yang menjalani hemodialisis (E. C. Fradelos et al., 2015). Spiritualitas mengandung pengertian hubungan manusia dengan Tuhannya dengan menggunakan medium sholat, puasa, zakat, haji, doa dan sebagainya. Selain itu, komponen spiritualitas juga terdiri dari hubungan manusia dengan alam, hubungan dengan dirinya sendiri dan hubungan dengan orang lain. Banyak peneliti juga berpendapat bahwa masalah spiritual merupakan masalah yang sangat penting bagi pasien yang menderita penyakit kronik yang mengancam jiwa, untuk itu perlu pendekatan dengan model biopsikososial-spiritual dalam merawat pasien gangguan spiritualitas akan menyebabkan gangguan berat secara psikologis termasuk keinginan bunuh diri (Mailani and Cholina, no date). Untuk itu perlu dilakukan pendekatan secara spiritual dalam meningkatkan kualitas hidup pasien penyakit ginjal kronik yang menjalani hemodialisis baik dari keluarga maupun tenaga medis yang mendampingi pasien dalam menjalani proses hemodialisis (Ottaviani et al., 2014). Penelitian ini dilakukan dengan pendekatan fenomenologi karena ingin mengeksplorasi mekanisme koping dengan pendekatan spiritual pasien yang menjalani hemodialisis. Selain itu, dengan menggunakan pendekatan fenomenologi akan diperoleh informasi baru yang lebih banyak dan komprehensif serta mendalam terkait spiritualitas pada pasien.

\section{METODE}

Penelitian ini kualitatif fenomenologi, sampel dalam penelitian ini sebanyak 15 orang partisipan yang dipilih secara purposive sampling sesuai dengan kriteria inklusi kriteria partisipan berusia lebih dari 25 tahun, menjalani hemodialisis lebih dari 3 bulan, kesadaran compos mentis dan reguler menjalani hemodialisa 2-3 kali seminggu. Saturasi data telah tercapai pada 10 partisipan namun untuk memperoleh variasi mendalam peneliti mengambil 15 partisipan. Pengumpulan data dilakukan melalui wawancara mendalam (in depth inteview) secara tatap muka sebanyak 1-2 kali dilaksanakan selama 30-60 menit di ruang hemodialisa. Proses wawancara menggunakan panduan berisi pertanyaan terbuka, alat perekam suara dan catatan lapangan. Analisis data menggunakan tahapan langka dari Colaizzi (1978) sebagai berikut hasil wawancara ditranskripkan verbatim, kemudian dianalisis secara bersamaan. Selanjutnya menentukan kategori dan pengkodean dan menyusun secara terstruktur membentuk subsub tema dan tema utama yang berkaitan dengan tujuan penelitian. Mengkonfirmasi kategori yang teridentifikasi pada rekan peneliti yang lain kemudian mengklarifikasi deskripsi tema kepada partisipan untuk divalidasi.

\section{HASIL}

Sebagian besar partisipan merupakan suku jawa dan menikah. Nilai URR partisipan bervariasi mulai $65.07 \%-84.09 \%$. tingat pendidikan bervariasi dan yang terbanyak yaitu SMA 8 partisipan. Berdasarkan pekerjaan partisipan terbanyak adalah tidak 
bekerja dan banyak yang berjenis kelamin perempuan.

Tabel 1. Karakteristik partisipan

\begin{tabular}{cccclllll}
\hline No & $\begin{array}{l}\text { Jenis } \\
\text { kelamin }\end{array}$ & $\begin{array}{l}\text { Usia } \\
\text { (tahun) }\end{array}$ & $\begin{array}{l}\text { Status } \\
\text { Perkawinan }\end{array}$ & Pekerjaan & Pendidikan & $\begin{array}{l}\text { Suku } \\
\text { Bangsa }\end{array}$ & $\begin{array}{l}\text { URR } \\
(\geq 65 \%)\end{array}$ & $\begin{array}{l}\text { Kode } \\
\text { partisipan }\end{array}$ \\
\hline 1 & L & 48 & Menikah & Wiraswasta & SMA & Jawa & $67,10 \%$ & P1 \\
\hline 2 & $\mathrm{P}$ & 56 & Menikah & PNS & S2 & Jawa & $65,67 \%$ & P2 \\
\hline 3 & $\mathrm{P}$ & 63 & Menikah & IRT & SD & Jawa & $84,09 \%$ & P3 \\
\hline 4 & $\mathrm{P}$ & 53 & Menikah & IRT & SMA & Jawa & $75,86 \%$ & P4 \\
\hline 5 & L & 40 & Menikah & Tidak bekerja & D III & Sunda & $65,07 \%$ & P5 \\
\hline 6 & P & 31 & Menikah & Tidak bekerja & SMP & Madura & $79,16 \%$ & P6 \\
\hline 7 & P & 58 & Menikah & Tidak bekerja & SMP & Jawa & $79,41 \%$ & P7 \\
\hline 8 & P & 48 & Menikah & Tidak bekerja & SMA & Jawa & $79,41 \%$ & P8 \\
\hline 9 & L & 57 & Menikah & Wiraswasta & SMA & Ambon & $79,41 \%$ & P9 \\
\hline 10 & L & 51 & Menikah & Wiraswasta & SMA & China & $72,30 \%$ & P10 \\
\hline 11 & P & 53 & Menikah & Tidak bekerja & SMP & Jawa & $73,21 \%$ & P11 \\
\hline 12 & P & 53 & Menikah & Wiraswasta & SMA & Jawa & $75,56 \%$ & P12 \\
\hline 13 & P & 51 & Menikah & Tidak bekerja & SD & Jawa & $73,78 \%$ & P13 \\
\hline 14 & L & 58 & Menikah & Wiraswasta & SMA & Jawa & $71,92 \%$ & P14 \\
\hline 15 & P & 55 & Menikah & Tidak bekerja & SMA & Jawa & $68,83 \%$ & P15 \\
\hline
\end{tabular}

Temuan tema dalam penelitian ini adalah pasrah, berdoa dan berdzikir seperti dapat dilihat pada tabel berikut:

Tabel 2. Temuan tema

\begin{tabular}{|c|c|c|}
\hline No & Tema & Sub Tema \\
\hline 1 & Kepasrahan & $\begin{array}{l}\text { 1. Menerima sakit } \\
\text { 2. Ikhlas }\end{array}$ \\
\hline 2 & Mendekatkan diri pada Tuhan & $\begin{array}{ll}\text { 1. } & \text { Berdoa } \\
\text { 2. } & \text { Berdzikir } \\
\text { 3. } & \text { Shalat }\end{array}$ \\
\hline
\end{tabular}


Tema 1: Kepasrahan

Kepasrahan yang dimaksudkan

partisipan adalah rasa pasrah atas apapun yang

berlaku terhadapnya baik secara spiritual

maupun emosional. Partisipan

mengungkapkan kepasrahan dengan menerima sakit sebagai ujian, ikhlas menghadapi

sakitnya, dan berserah pada Tuhan. Partisiapan

menganggap bahwa ujian yang diberikan

padanya adalah penggugur dosa dosa dimasa lalu.

1) Menerima sakit

Partisipan mengungkapkan penerimaan

terhadap sakit dinyatakan oleh 10

partisipan seperti penggalan transkip

berikut :

" mau gimana lagi pak, saya cuma

bisa pasrah, toh sakit ini juga ujian

buat saya, saya harus tetap kuat

mengahadapinya" (P09)

"kita cuma manusia, serahkan segalanya sama Tuhan, maka tidak

akan ada yang sia-sia, menerima segala cobaan termasuk sakit ini" (P13)

2) Ikhlas

Partisipan mengungkapkan rasa ikhlas yang dinyatakan oleh 11 partisipan seperti penggalan transkip berikut:

" diikhlaskan saja pak, semuanya pasti ada hikmahnya, sehat sakit adalah rezeki" (P04)

" saya ikhlas pak diberi sakit ini, ambil sisi positifnya saja, tetap

berusaha berobat sampai diberi

kesembuhan atau kematian yang lebih dulu" (P06)

Tema 2 : Mendekatkan Diri pada Tuhan Mendekatkan diri pada Tuhan diartikan sebagai pendekatan partisipan berupa kegiatan ibadah berdoa, berdzikir dan shalat.

1) Berdoa

Secara keseluruhan partisipan menyatakan berdoa seperti penggalan transkip berikut :

"saya berdoa terus minta kesembuhan seperti sediakala karena masih banyak yang harus saya selesaikan dalam hidup ini pak" (P01)

" tiada lain selain berdoa agar diberikan yang terbaik dan bisa kayak dulu lagi "(P05)

2) Shalat

Sebanyak 13 partisipan menyatakan melakukan shalat dalam mengatasi stress yang dialami seperti penggalan transkip berikut : "shalat pak, kalo dah gitu rasanya nyaman sekali gak mikir anehaneh"(P11)

" setiap hari saya shalat sunnah dan wajib, tahajud pun saya lakukan agar

3) Berdzikir diberi ketentraman jiwa raga" (P07)

Sebanyak 12 partisipan melakukan kegiatan berdzikir untuk mengatasi stress seperti penggalan transkip berikut : "dzikir adalah cara terbaik mengatasi pikiran kacau dan saya selalu lakukan itu hasilnya pun hati terasa lebih tentram" (P15)

"berdzikir terus sampe ketiduran biasanya dan akhirnya menjadi kebiasaan" (P02)

\section{PEMBAHASAN}

Koping merupakan apa yang dilakukan oleh individu untuk menguasai situasi yang dinilai sebagai suatu tantangan/luka/kehilangan/ ancaman. Koping lebih mengarah pada yang dilakukan orang untuk mengatasi tuntutan-tuntutan yang penuh tekanan atau yang membangkitkan emosi . Reaksi individu terhadap stressor emosional yang dialaminya dapat menentukan koping strategi yang digunakannya. Berbagai sumber daya seperti keyakinan, religius, social network, uang, energi personal dan rasa aman emosional mungkin dapat digunakan untuk mengatasi stress yang dialami oleh lansia (Rantakokko and Wilkie, 2017).

Terdapat beberapa prilaku koping yang digunakan dalam beradaptasi terhadap penyakit kronis yaitu pengingkaran (denial), penerimaan (acceptance), dan pemecahan masalah (White, Richter \& Fry C, 2012). Ekspresi spiritual yang terjadi pada klien hemodialisis berupa kategori bersyukur, pasrah, meningkatkan ibadah. Ekspresi ini dialami oleh seluruh partisipan. Pada saat wawancara partisipan mengatakan bersyukur karena dengan sakit merasa masih bisa menjalankan ibadah, ada yang menganggap ini suatu anugerah karena dengan kondisi saat ini partisipan merasa grafik imannya meningkat, dan dengan sakit ada juga partisipan yang menganggap bahwa sakit dapat mengurangi dosa-dosa(Carlson et al., 2014). Partisipan lain mengatakan bahwa ada sesuatu yang Allah berikan kepada mereka, karena mereka tidak meninggal dari dulu, dengan demikian partisipan bersyukur diberikan kesempatan untuk bertobat. Partisipan juga mengatakan bahwa dulu Allah memberikan nikmat lebih 
besar dari sekarang, namun partisipan tidak bisa mensyukurinya.

Ekspresi spiritual lainnya berupa rasa pasrah. Partisipan pasrah dan ihlas menerima kondisi apa adanya. Partisipan juga mengatakan sudah takdirnya cuci darah dan ihlas menjalani karena sudah nasib partisipan. Hasil penelitian ini sesuai dengan penelitian yang dilakukan oleh Gibson (1995) terhadap 20 orang klien yang menjalani hemodialisis, dimana ditemukan kategori yang sama yaitu pasrah kepada Tuhan. Ungkapan lain dari partisipan terkait dengan ekspresi spiritual adalah partisipan mengatakan kondisi klien membuat klien menjadi lebih meningkat dalam menjalankan ibadah. Dengan kondisi yang dihadapi, partisipan merasa lebih meningkat dalam hal kualitas ibadah.

Hasil penelitian ini menemukan makna baru yang dirasakan oleh partisipan setelah di diagnosis gagal ginjal tahap akhir dan harus menjalani hemodialisis yaitu merasa kualitas spiritual meningkat. Taylor, Lilis \& Lemone mengatakan spiritualitas adalah segala sesuatu yang menyinggung tentang hubungan manusia dengan sumber kekuatan hidup atau yang maha memiliki kekuatan; Spiritualitas adalah proses menjadi tahu, cinta dan melayani Tuhan; spiritualitas adalah suatu proses yang melewati batas tubuh atau fisik dan pengalaman energy universal, dimana agama bisa merupakan bagian dari spiritualitas (E. C. Fradelos et al., 2015). Sedangkan Craven \& Hirnle mengatakan spiritualitas adalah kualitas atau kehadiran dari proses meresapi atau memaknai, integritas dan proses yang melebihi kebutuhan biopsikososial, sementara menurut Murray \& Zentner inti dari spiritual adalah kualitas dari suatu proses menjadi lebih religius, berusaha mendapatkan inspirasi, penghormatan, perasaan kagum, memberi makna dan tujuan yang dilakukan oleh individu yang percaya maupun yang tidak percaya kepada Tuhan (Rohini and Ezhilarasu, 2016).

Pada penelitian ini didapatkan hasil bahwa semua partisipan mengatakan lebih mendekatkan diri kepada Tuhan dibandingkan sebelum mengalami gagal ginjal dan hemodialisis. Mendekatkan diri kepada Tuhan dilakukan oleh partisipan dengan menjalankan aturan agama dan tidak berbuat hal yang dilarang oleh agama yang diyakininya(Abbasi et al., 2017). Partisipan mengungkapkan dengan kondisinya saat ini merasa bahwa lebih sering beribadah, dimana sebelumnya partisian kadang sering meninggalkan solat, namun dengan kondisi saat ini partisipan mengatakan bahwa selalu solat tepat waktu dan tidak pernah meninggalkan solatnya. Selain menjalankan solat partisipan juga meningkat kegiatan spiritual dengan terus memuja Tuhan dengan berzikir, mengikuti kegiatan keagamaan di mesjid, yang mana sebelum dinyatakan gagal ginjal hal ini tidak pernah dilakukan. Partisipan juga menungkapkan bahwa sekarang ini lebih memikirkan kehidupan untuk bekal akhirat dan berusaha untuk berbuat baik sesama manusia (E. Fradelos et al., 2015).

Partisipan lain mengatakan bahwa setelah dinyatakan gagal ginjal dan menjalani hemodialisis, partisipan merasakan lebih bersyukur, karena dengan kondisi saat ini membuat partisipan lebih dekat dengan sang pencipta, merasa Tuhan sayang padanya, karena masih diberi kesempatan untuk beribadah dan bertobat. Partisipan mengatakan kalau seandainya tidak sakit seperti ini, partisipan tidak tahu berapa banyak dosanya, karena saat sehat betapa banyak nikmat yang diberikan oleh Tuhan kepadanya tapi partisipan tidak mensyukurinya. Dengan kondisi saat ini partisipan menyadarinya dan bersyukur atas nikmat yang diberikan oleh Tuhan kepadanya, rasa syukur itu diwujudkan oleh partisipan dengan lebih mendekatkan diri kepada Tuhan(Crockett et al., 2018).

Seseorang akan memperoleh manfaat yang besar ketika seseorang menggunakan kepercayaannya sebagai kekuatan yang dapat memberikan dukungan pada kesehatannya. Hal ini sesuai dengan apa yang diungkapkan oleh salah seorang partisipan, dimana partisipan mengatakan bahwa dengan lebih mendekatkan diri kepada Tuhan yaitu dengan menjalankan solat tahajut ditengah malam, partisipan merasakan bahwa keluhan fisik (acites) akibat dari penyakitnya menjadi berkurang, sehingga partisipan merasa bahwa semakin dekat dengan Tuhan membuat dirinya semakin yakin bahwa Tuhan sayang padanya (Ottaviani et al., 2014).

Partisipan mengatakan bahwa kualitas hidup secara spiritual dirasakan lebih meningkat dengan cara mendekatkan diri kepada Tuhan dan berbuat baik. Meningkatnya kualitas spiritual dalam hal ini ketaatan partisipan dalam menjalankan ibadah sangat berpengaruh terhadap mekanisme coping dari partisipan, sehingga partisipan lebih mudah beradaptasi dan menerima penyakitnya . Hal ini didukung oleh hasil penelitian dimana dari hasil penelitian dikatakan bahwa klien yang dirawat di rumah sakit berbasis agama memiliki mekanisme coping lebih baik dibandingkan 
dengan pasien yang dirawat di rumah sakit tentara (Roberti et al., 2018).

\section{KESIMPULAN DAN SARAN}

Kesimpulan

Mekanisme koping dengan pendekatan spiritual dirasakan oleh partisipan memberikan dampak pada ketenangan jiwa dan raga sehingga tidak lagi dirasakan kecemasan yang begitu mengganggu. Untuk itu sebagai langkah awal perawat dalam memberikan asuhan keperawatan terkait kecemasan adalah dengan pendekatan spiritual.

Saran

Pembekalan spiritual lebih banyak dilakukan waktu awal pasien penyakit ginjal kronik menjalani hemodilisis melalui bimbingan dari pembina rohani sehingga meningkatkan koping dari pasien.

\section{DAFTAR PUSTAKA}

Abbasi, M. et al. (2017) 'Original Article', 4(1), pp. 10-15.

Arafah, M. et al. (2017) 'PENGALAMAN SPRITUAL PASIEN KANKER KOLON DENGAN KOLOSTOMI PERMANEN : STUDI FENOMENOLOGI', 2.

Carlson, L. E. et al. (2014) 'Tailoring mindbody therapies to individual needs: Patients' program preference and psychological traits as moderators of the effects of mindfulness-based cancer recovery and supportiveexpressive therapy in distressed breast cancer survivors', Journal of the National Cancer Institute Monographs, 2014(50), pp. 308-314. doi: 10.1093/jncimonographs/lgu034.

Crockett, J. E. et al. (2018) 'A Phenomenological Inquiry of Identity Development, Same-Sex Attraction, and Religious Upbringing', 63(April), pp. 91-109. doi: 10.1002/cvj.12075.

Fradelos, E. et al. (2015) 'The Effect of Spirituality on Quality of Life of Patients with Chronic Kidney Disease and Its Correlation with the Mental Health Status and Cognitive Perception for Their Illness . Study Protocol'. doi: 10.4236/oalib.1101783.

Fradelos, E. C. et al. (2015) 'INTEGRATING CHRONIC KIDNEY DISEASE PATIENT' S SPIRITUALITY IN THEIR CARE : HEALTH BENEFITS AND RESEARCH PERSPECTIVES',
27(October), pp. 354-358. doi: 10.5455/msm.2015.27.354-358.

Mailani, F. and Cholina, T. S. (no date) 'Pengalaman Spiritualitas pada Pasien Penyakit Ginjal Kronik yang Menjalani Hemodialisis Spiritual Experience of Chronic Renal Failure Patient Undergoing Hemodialysis', 3(April 2015), pp. 11-17.

Ottaviani, A. C. et al. (2014) 'Hope and spirituality among patients with chronic kidney disease undergoing hemodialysis : a correlational study 1', 22(2), pp. 248-254. doi: 10.1590/0104-1169.3323.2409.

Rantakokko, M. and Wilkie, R. (2017) 'The role of environmental factors for the onset of restricted mobility outside the home among older adults with osteoarthritis : a prospective cohort study', pp. 1-9. doi: 10.1136/bmjopen2016-012826.

Roberti, J. et al. (2018) 'Work of being an adult patient with chronic kidney disease : a systematic review of qualitative studies', pp. 1-29. doi: 10.1136/bmjopen-2018-023507.

Rohini, T. and Ezhilarasu, P. V (2016) 'Lived Experience of Patients Undergoing Hemodialysis : Quality of Life Perspective', 3(2).

Shahgholian, N. and Yousefi, H. (2018) 'The lived experiences of patients undergoing hemodialysis with the concept of care : a phenomenological study'. BMC Nephrology, 4, pp. 1-7. 